\title{
Diagnostic efficacy of Widal slide agglutination test against Widal tube agglutination test in enteric fever
}

Ujjwala N. Gaikwad, Monali Rajurkar ${ }^{1}$

Department of Microbiology, All India Institute of Medical Sciences, Tatibandh, Raipur,

${ }^{1}$ Microbiology, Chandulal Chandrakar Memorial Medical College, Bhilai, Chhattisgarh, India

Address for the Correspondence: Dr. Ujjwala N. Gaikwad, Department of Microbiology,

All India Institute of Medical Sciences, G E Road, Tatibandh, Raipur - 492 099, Chhattisgarh, India.

E-mail: ujugaikwad@gmail.com

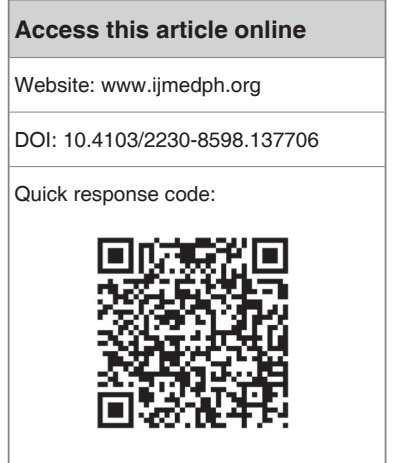

Introduction: Enteric fever is an endemic disease in India and warrants rapid and affordable diagnosis. The Widal slide agglutination test is a commonly used rapid screening test for this purpose. The literature available on its diagnostic ability in comparison to the tube agglutination test is however scanty. Hence, this study aims to evaluate the efficacy of the Widal slide agglutination test and the tube agglutination test for the diagnosis of enteric fever. Materials and Methods: A total of 1470 sera were collected during the study period of one year from patients having pyrexia of unknown origin. All the samples were tested for the presence of anti $O$ and anti $\mathrm{H}$ agglutinins against $S$. typhi and $S$. paratyphi $A$ by semi quantitative slide and quantitative tube agglutination tests as per standard protocols. The titers of 1:80 (O agglutinins) and 1:160 ( $\mathrm{H}$ agglutinins) were taken as the significant titer for the diagnosis of enteric fever. The results of the slide agglutination test were compared with the tube agglutination test and analyzed using Fisher's exact test. The sensitivity, specificity, positive and negative predictive values of slide agglutination were calculated using the tube agglutination method as a standard for comparison. Results: Of the 294 slide positive samples, 209 (71.1\%) samples tested negative by the tube agglutination test. The sensitivity, specificity, positive and negative predictive values for the slide agglutination test were observed to be $100 \%(\mathrm{Cl}$ 95.75-100\%), 84.91\% (Cl 82.93-86.73\%), 28.91\% (Cl 23.84-34.45\%) and 100\% (Cl 99.69-100\%) respectively. Conclusion: Serological diagnosis of enteric fever should always be confirmed by the tube agglutination test rather than depending solely upon the rapid slide agglutination test results.

Key words: Paratyphoid fever, rapid test, typhoid fever, Widal test

\section{INTRODUCTION}

Enteric fever is an important cause of morbidity in many regions of the world, with an estimated 13 million cases occurring annually in Asia alone. ${ }^{[1]}$ Estimates suggest an incidence rate of more than 21.5 million cases globally in the year $2000 .{ }^{[2]}$

In India, enteric fever is caused by Salmonella enterica serotype Typhi and Paratyphi A. Serotypes B and C are very rare. Laboratory diagnosis mainly depends upon isolation of causative agents from specimens like blood and bone marrow. A blood culture gives positive results in 73-97\% cases before the use of antibiotics. ${ }^{[3]}$ However, the availability of microbiological culturing facilities is often limited in many typhoid endemic regions and blood cultures can be negative when patients have received prior antibiotic therapy. ${ }^{[1]}$ Hence, serological diagnosis using Widal test is relied upon in many cases.

Laboratories in industrialized countries have stopped performing the assay due to many reasons which include the low prevalence of enteric fever, adequate hygiene and improved sanitary measures, better isolation facilities for bacteria, and the relatively low sensitivity and specificity of the Widal test. ${ }^{[4]}$ However, in developing countries like India, the Widal test continues to be a popular test for the diagnosis of suspected enteric fever in an acute phase as it is simple, gives rapid results, is easily available and affordable. ${ }^{[5]}$

Two types of agglutination techniques are available: the slide test and the tube test. The slide test first introduced by Welch et al., ${ }^{[6]}$ is a rapid test and thus used as a screening procedure. The tube 
agglutination test requires greater technical work than the more rapid slide test, and is a macroscopic test. It is useful to clarify erratic or equivocal agglutination reactions obtained by the more rapid slide test. ${ }^{[4]}$ However, since it takes 18-24 hours to get the results; practically the diagnosis is often formed on the basis of the slide agglutination results which are available within minutes. Using slide agglutination as a screening test without confirming the results by tube agglutination may lead to a false diagnosis of enteric fever and an avoidable introduction of antibiotic therapy.

The present study was therefore designed to assess the efficacy of the slide agglutination technique in diagnosing enteric fever accurately compared to the tube agglutination technique.

\section{MATERIALS AND METHODS}

The cross-sectional study study was conducted over a period of one year from May 2011 to April 2012 after obtaining approval from the institutional ethics committee.

All the blood samples requisitioned and received in the microbiology laboratory for Widal test from patients suspected as having enteric fever during the study period were included in the study. The serum was separated from each blood sample following all standard precautions. The sera were then subjected to the Widal test by the slide agglutination method. The test was performed as per the manufacturer's instructions (Span diagnostics Ltd.).

Briefly, $50 \mu$ l of antigen was placed upon the slide provided in the kit followed by addition of $50 \mu \mathrm{l}$ of serum. The slide was rocked gently for mixing. Since observation of agglutination in the form of visible clumps may have observer's bias, the result of the agglutination reaction was scored as 0 (no agglutination), $1+(25 \%$ agglutination), $2+(50 \%$ agglutination $), 3+(75 \%$ agglutination $)$ or $4+(100 \%$ agglutination). The sample was labeled as positive if the serum exhibited $\geq 2+$ or $50 \%$ agglutination. ${ }^{[4]}$ The positive results in the neat sample were titrated for the amount of antibodies by using the semi-quantitative Widal test as per manufacturer's recommendations. The titers of 1:80 and 1:160 were taken as cut off titers to determine positivity towards $\mathrm{O}$ and $\mathrm{H}$ antigens.

All the samples were then subjected to the tube agglutination test to find out exact titer of antibodies. The serum was diluted in doubling dilutions. $0.5 \mathrm{ml}$ of each dilution was then added to a row of Felix tubes containing the same quantity of $S$. typhi $O$ antigen and two rows of Dreyers' tubes containing the same quantity of $S$. typhi $\mathrm{H}$ and $S$. paratyphi $A$ antigens. The rack containing all the tubes was then incubated at $37^{\circ} \mathrm{C}$ in a water bath overnight. Macroscopic agglutination was noted and recorded on the following day after keeping the rack at room temperature. The highest dilution of serum giving visible agglutination was calculated and matched against the currently used local cut off titer as mentioned above, to confirm positivity. At the end, the results of both slide and tube agglutination test were compared and analyzed using Fisher's exact test.

\section{RESULTS}

A total of 1470 samples were received during the study period. The samples were first subjected to the slide agglutination test. Of these, $1176(80 \%)$ samples were negative while $294(20 \%)$ samples were found to be positive. All the samples were then subjected to the tube agglutination test. All slide negative samples were confirmed as negative by tube agglutination as none of them showed significant titer for both $\mathrm{O}$ and $\mathrm{H}$ antibodies on tube agglutination test.

Out of 294 (20\%) slide positive samples (with significant titers on semiquantitative test), $85(28.9 \%)$ samples were tube agglutination positive, whereas the remaining 209 (71.1\%) had titers below significant level on tube agglutination. It can thus be inferred that actual positivity by both slide and tube test was seen in only 5.78\% samples while $14.21 \%$ samples were incorrectly labeled as positive by slide agglutination tests since they actually had titers less than the significant levels [Table 1].

Sensitivity, specificity, positive predictive value (PPV) and negative predictive value (NPV) were calculated as shown in Table 2. Of the total samples positive by slide Widal for TO antigen, true positives were only $11 / 117$ (9.4\%). For TO, TH, true positives were 65/167 $(38.92 \%)$ and for TO, AH, true positives were 5/10 (50\%).

\section{DISCUSSION}

The definitive diagnosis of enteric fever depends on the isolation of organisms from blood, bone marrow or other body fluids. The role of the Widal test has been to increase the index of suspicion for the presence of enteric fever by demonstrating positive agglutination during the acute and convalescent period of infection with evidence of a four-fold rise of antibody titer. ${ }^{[4]}$ The slide Widal test has the advantage of being highly practicable and low cost. ${ }^{[7]}$ The tube agglutination test requires at least overnight incubation and more technical work than the rapid slide test.

According to Hoffman et al., ${ }^{[8]}$ the results of a single Widal test, tube dilution, micro-agglutination or slide agglutination are virtually un-interpretable unless the sensitivity and specificity as well as the

\begin{tabular}{|c|c|c|c|c|c|c|}
\hline & & \multicolumn{4}{|c|}{ Tube Widal test (titer) } & \multirow[b]{2}{*}{ Total } \\
\hline & & $\begin{array}{c}\text { TO } \\
\text { positive } \\
(\geq 1: 80)\end{array}$ & $\begin{array}{c}\text { TO, TH } \\
\text { positive } \\
(\mathrm{TO} \geq \\
1: 80 \mathrm{TH} \\
\geq 1: 160 \text { ) }\end{array}$ & $\begin{array}{c}\text { TO, } \mathrm{AH} \\
\text { positive } \\
(\mathrm{TO} \geq \\
1: 80 \mathrm{AH} \\
\geq 1: 160)\end{array}$ & $\begin{array}{c}\text { Negative } \\
\text { (TO < } \\
1: 80 \mathrm{TH}, \\
\mathrm{AH}< \\
1: 160) \\
\end{array}$ & \\
\hline \multirow{4}{*}{$\begin{array}{l}\text { Slide } \\
\text { Widal } \\
\text { test } \\
\text { (titer) }\end{array}$} & $\begin{array}{l}\text { TO positive } \\
(\geq 1: 80)\end{array}$ & 11 & 0 & 0 & 106 & 117 \\
\hline & $\begin{array}{l}\text { TO, TH positive } \\
(\mathrm{TO} \geq 1: 80, \\
\mathrm{TH} \geq 1: 160)\end{array}$ & 4 & 65 & 0 & 98 & 167 \\
\hline & $\begin{array}{l}\text { TO, AH positive } \\
\text { ( } T O \geq 1: 80 \\
A H \geq 1: 160)\end{array}$ & 0 & 0 & 5 & 5 & 10 \\
\hline & Total & 15 & 65 & 5 & 209 & 294 \\
\hline
\end{tabular}




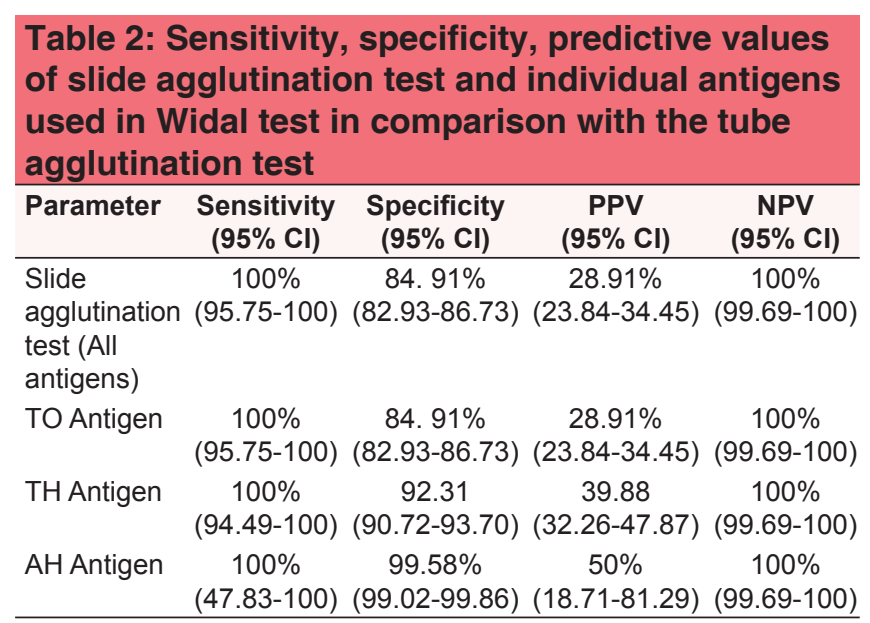

$\mathrm{PPV}=$ Positive predictive value, NPV = Negative predictive value, $\mathrm{Cl}=$ Confidence interval

predictive values of the test for the specific laboratory and patient population are known.

In our study, the slide agglutination test performed well as a screening test $(P<0.001)$ since we observed very good overall sensitivity $(100 \%)$ and NPV $(100 \%)$. However, the specificity was relatively low (84. 91\%), more so when TO antigen alone was considered. For $\mathrm{H}$ agglutination, the specificity was better than $\mathrm{O}$ agglutination (92.31\% for $\mathrm{TH}$ and $99.58 \%$ for $\mathrm{AH}$ ). We did not test for S. paratyphi $B$ antigen since enteric fever due to $S$. paratyphi $B$ is not a common occurrence in our geographical location.

It has been argued that the positive predictive value (PPV) is the most important measure of a clinical diagnostic method since it represents the proportion of patients with positive test results that are correctly diagnosed. ${ }^{[9]}$ In our study, the PPV was significantly low for all the antigens (TO-28.91\%, TH-39.8\%, AH-50\%). This clearly proves that, although the slide agglutination test is useful in screening out negative samples, the positivity expressed by it is not always helpful in diagnosing the disease correctly.

Keddy et al., ${ }^{[10]}$ has compared four different techniques for the diagnosis of enteric fever, of which the slide agglutination test performed the worst. It had a very poor specificity (O-3.6\%, and $\mathrm{H}-50 \%$ ) and low PPV (O-25\%, H-53.8\%) and NPV (O-68.65, $\mathrm{H}-77.8 \%$ ) even though it was performed under optimal conditions in a National Reference Laboratory. This poor performance was further compounded by substantial inter-test variability, which suggests that in a field situation, results would not be comparable between study sites. Hence, Keddy et al. ${ }^{[10]}$ has suggested that the slide agglutination test should not be used as a diagnostic tool. Although the sensitivity and specificity of the $\mathrm{H}$ slide agglutination test appeared to be greater, this was offset by the inconsistent results obtained with the $\mathrm{O}$ slide agglutination. This was obvious in the present study as well.

High false positivity exhibited by slide agglutination in this study can be attributed to the endemicity of the disease in the study area and possible presence of cross reacting antibodies of other bacterial and non-bacterial infections. If the slide agglutination test is solely relied upon for diagnosis, a significant number of samples would have been falsely labeled as positive and clinicians would have started antimicrobial chemotherapy in otherwise healthy individuals. This could lead to serious consequences by unnecessarily pressuring the normal gut flora to develop antibiotic resistance. Hence, the use of slide agglutination test for diagnosis of enteric fever remains questionable.

It has been rightly stated by Welch et al., [6] "No Widal test is infallible and it is not likely that any will be developed that will lower the validity of the isolation of the etiological agent." A culture is and will remain as the gold standard for the diagnosis of enteric fever. Unfortunately, in our study we could not use it as a standard for comparison because very few results of blood culture were available out of all the samples. However, it has been proved by many studies that the Widal agglutination test is still of significant diagnostic value, particularly in an area where there is a reasonably high suspicion (prior probability) of enteric fever, provided judicious interpretation of the test is made. ${ }^{[11,12]}$ At the same time, it is also true that if going for the slide agglutination test instead of the standard tube Widal test, it should always be interpreted with reference to the results of the tube agglutination test and clinical data available. ${ }^{[13]}$

\section{CONCLUSION}

The high false positivity and low positive predictive value shown by the slide agglutination test is to caution that the results of slide agglutination should not be solely relied upon for diagnosis and treatment of enteric fever. Performing slide agglutination test is actually a common practice in many resource-constrained laboratories hence if at all it is to be used, the results should always be confirmed by the tube agglutination test and interpreted with reference to clinical data.

\section{REFERENCES}

1. House D, Wain J, Ho VA, Diep TT, Chinh NT, Bay PV, et al. Serology of typhoid fever in an area of endemicity and its relevance to diagnosis. J Clin Microbiol 2001;39:1002-7.

2. Crump JA, Luby SP, Mintz ED. The global burden of typhoid fever. Bull World Health Organ 2004;82:346-53.

3. Wilke A, Ergonul O, Bayar B. Widal test in diagnosis of typhoid fever in turkey. Clin Diagn Lab Immunol 2002;9:938-41.

4. Olopoenia LA, King AL. Widal agglutination test - 100 years later: Still plagued by controversy. Postgrad Med J 2000;76:80-4.

5. Ley B, Mtove G, Thriemer K, Amos B, von Seidlein L, Hendriksen I, et al. Evaluation of the Widal tube agglutination test for the diagnosis of typhoid fever among children admitted to a rural hospital in Tanzania and a comparison with previous studies. BMC Infect Dis 2010;10:180.

6. Welch $\mathrm{H}$, Lee Mickle F. A rapid slide test for the serological diagnosis of typhoid and paratyphoid fevers. Am J Public Health Nations Health 1936;26:248-55.

7. Handojo I, Edijanto SP, Probohoesodo MY, Mahartini NN. Comparison of the diagnostic value of local Widal slide test with imported Widal slide test. Southeast Asian J Trop Med Public Health 2004;35:366-70.

8. Hoffman SL, Flanigan TP, Klancke D, Leksana B, Rockhill RC, Punjabi NH, et al. The Widal slide agglutination test, a valuable rapid diagnostic test in typhoid fever patients at the infectious disease hospital in Jakarta. Am J Epidemiol 1986;123:869-75.

9. Altman DG, Bland JM. Diagnostic tests 2: Predictive values. BMJ 1994,309:102. 
10. Keddy KH, Sooka A, Letsoalo ME, Hoyland G, Chaignat CL, Morrissey AB, et al. Sensitivity and specificity of typhoid fever rapid antibody tests for laboratory diagnosis at two sub-Saharan African sites. Bull World Health Organ 2011;89:640-7.

11. Pang T, Puthucheary SD. Significance and value of the Widal test in the diagnosis of typhoid fever in an endemic areas. J Clin Pathol 1983;36:471-5.

12. Parry CM, Wijedoru L, Arjyal A, Baker S. The utility of diagnostic tests for enteric fever in endemic locations. Expert Rev Anti Infect Ther 2011;9:711-25.
13. Wain J, Hosoglu S. The laboratory diagnosis of enteric fever. J Infect Dev Ctries 2008;2:421-5.

How to cite this article: Gaikwad UN, Rajurkar M. Diagnostic efficacy of Widal slide agglutination test against Widal tube agglutination test in enteric fever. Int $\mathrm{J}$ Med Public Health 2014;4:227-30.

Source of Support: Nil, Conflict of Interest: None declared. 